\title{
Medical Image of the Week: Empyema
}

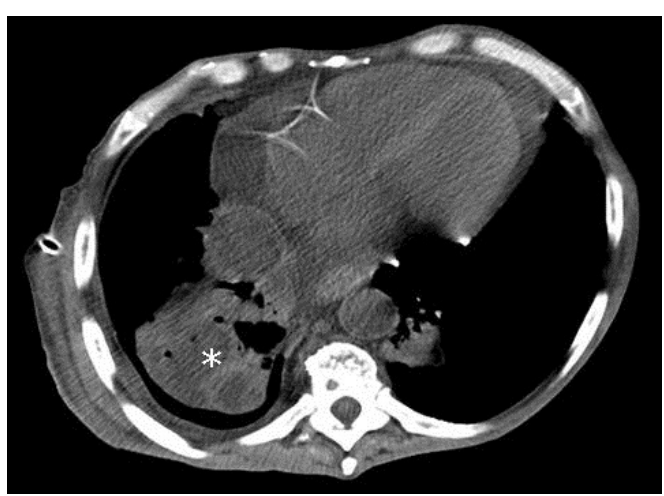

Figure 1. Admission thoracic CT showing a low density collection in the right lung likely from necrosis $\left(^{*}\right)$.
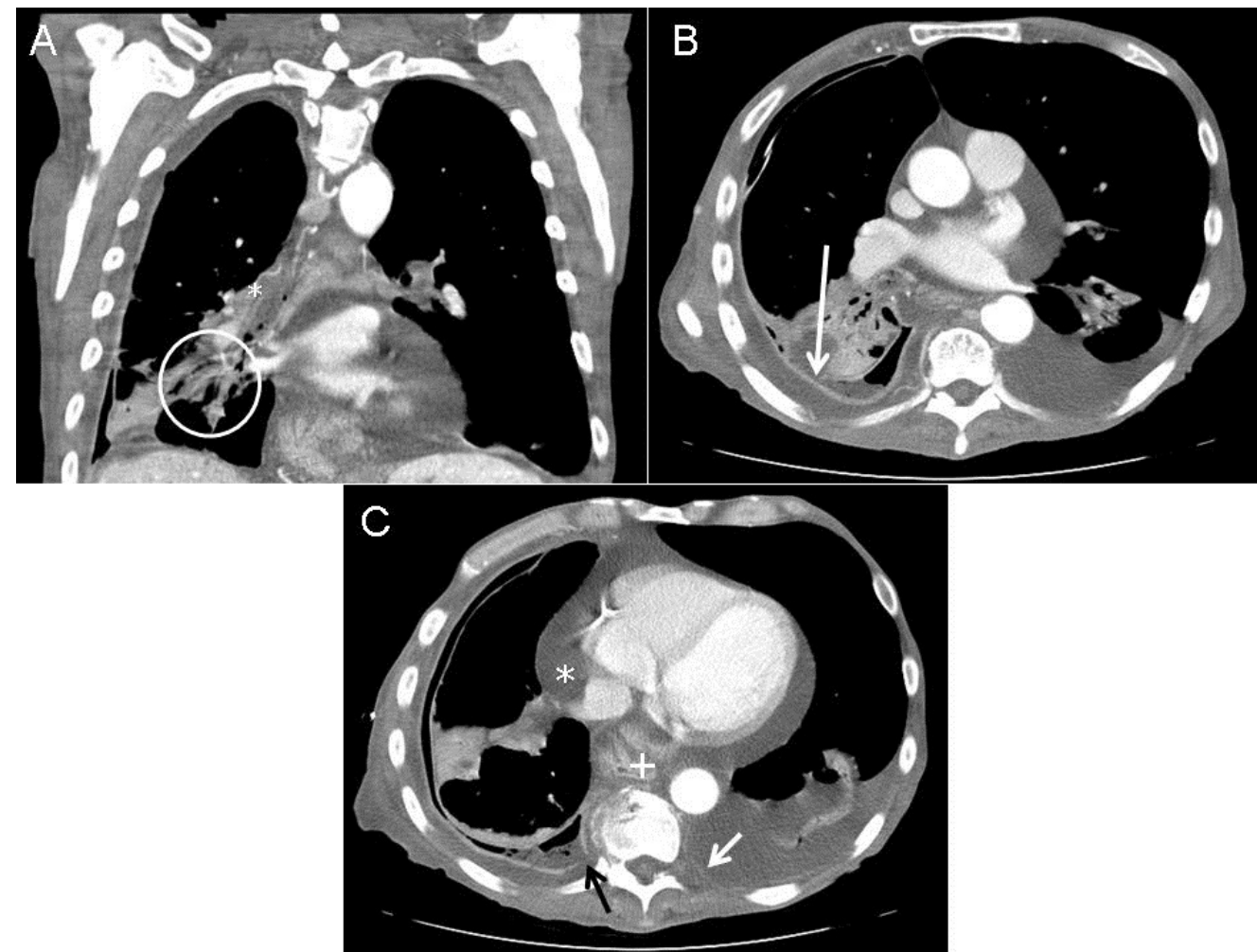

Figure 2. Selected views from the thoracic CT obtained 1 week after admission. Panel A: Architectural distortion (white circle) suggests necrotizing pneumonia. Note fluid within the bronchus intermedius $\left(^{*}\right)$. Panel B: Defect in visceral pleura (arrow) with decompression of parenchymal necrosis into the pleural space. Note enhancement and thickening of both pleural layers. Panel C: Defect in parietal pleura (black arrow) with fluid extending into the extrapleural space. Pericardial effusion $\left({ }^{*}\right)$, new left pleural effusion and left parietal pleura enhancement (white arrow) suggests spread of infection. Incidental hiatal hernia (+). 
A 71 year-old man with chronic obstructive pulmonary disease (COPD) presents to the emergency department complaining of dyspnea after recent admission for pneumonia. Chest CT shows a low density collection in the right lung suggesting necrosis (Figure 1). A CT obtained 1 week after admission (Figure 2) shows progression to empyema.

Management of empyema can be difficult. If the fluid cannot be removed with a therapeutic thoracentesis, a chest tube should be inserted and consideration be given to the intrapleural instillation of fibrinolytics (1). If the loculated effusion persists, the patient should be subjected to video-assisted thoracoscopic surgery. If the lung cannot be expanded with this procedure, a full thoracotomy with decortication should be performed. The definitive procedure should be performed within fourteen days.

Jason R. Young MD and David L. August, MD

Department of Radiology

Maricopa Integrated Health System

Phoenix, AZ

\section{Reference}

Light RW. Parapneumonic effusions and empyema. Proc Am Thorac Soc. 2006;3(1):7580. [CrossRef] [PubMed] 